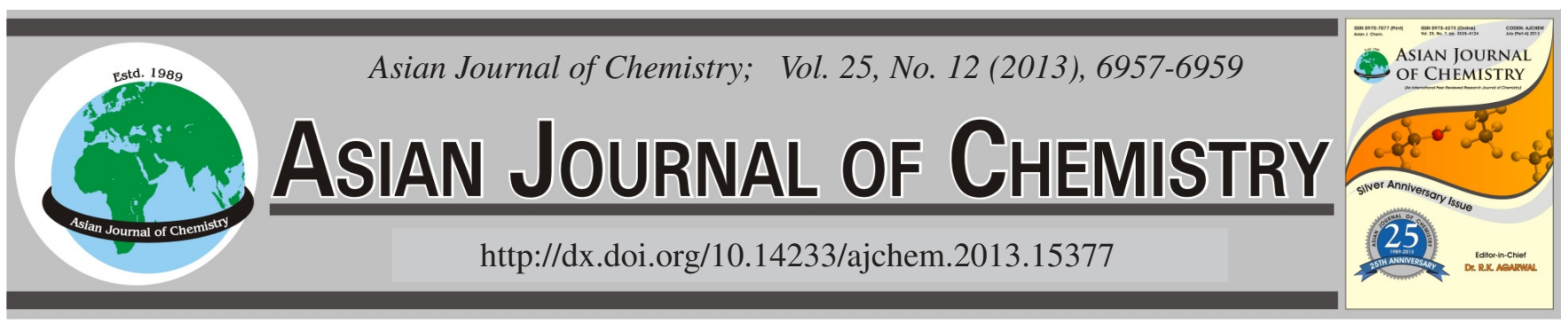

\title{
Effects of Sulfur Components on Crossing Point Temperature of Coal
}

\author{
Xuyao Qi ${ }^{*}$, Deming Wang, Haihui Xin and Guansheng Qi
}

Faculty of Safety Engineering, China University of Mining and Technology, Xuzhou, China

*Corresponding author: Fax: +86 516 83590598; Tel: +86 13585490927; E-mail: qixuyao@gmail.com

The crossing point temperature of initial and blended dried coal samples were tested. The weight percentages of FeS $S_{2}$ in blended coal samples were 3,5 and $7 \% .50 \mathrm{~g}$ of coal particles ranging from $0.18 \mathrm{~mm}$ to $0.38 \mathrm{~mm}$ in size were put into a coal vessel attached at the center of oven. The temperature program increased the temperature at a rate of $0.8^{\circ} \mathrm{C} / \mathrm{min}$. Dry-air was permitted to flow into the coal vessel at different rates. The results indicate that the effects of sulfur components depend on reaction conditions and coal ranks. The reactivity of sulfur components in the coal is low under dry and low temperature conditions. These components form a film that covers the coal surface and slightly inhibits the self-heating of the coal. The inhibition degrees are different for different ranks of coal, which is due to the types and amount of active groups. It is usually more obvious for lower ranks of coal.

Key Words: Coal, Crossing point temperature, Sulfur component, Spontaneous combustion.

\section{INTRODUCTION}

Crossing point temperature (CPT) is an important parameter in spontaneous combustion of coal. In coal self-heating, the rate of the rise in coal temperature during coal oxidation would become greater under appropriate conditions. The temperature at the point where the coal temperature begins to exceed the surrounding temperature is the crossing point temperature of coal. It has been used to evaluate the propensity of coal to spontaneous combustion by some investigators ${ }^{1-3}$.

During coal self-heating, many factors may influence the rising of coal temperature ${ }^{4,5}$. Sulfur components in coal is one of the factors. As known, there are some sulfur components in coal, which include organic and inorganic sulfur ${ }^{6}$. Though the affecting mechanism of sulfur components on coal oxidation is still disputed until now, the important role of sulfur components in coal self-heating has been confirmed by many investigators $^{7-10}$. At this time, the effects of some factors have been analyzed by different investigators, such as air humidity and flow rate, surrounding heating rate, volatile matter, oxygen content, moisture content, ash content, coal particle size and inhibitor additive $e^{11-13}$. However, the effect of sulfur components on crossing point temperature is not very clear at this time. This paper analyzes the effects of sulfur on temperature rising of coal and the value of crossing point temperature.

Different methods have been used to test crossing point temperature of coal in previous literatures. An oil-bath method ran at a constant heating rate was initially used in $1915^{14}$. Other investigators modified the testing method through altering reaction atmosphere, heating bath, coal reaction vessel, etc. ${ }^{3,16}$. For accurate and quick testing of crossing point temperature, a new experimental system is explored in this paper based on the existing method.

\section{EXPERIMENTAL}

Coal samples: Two different ranks of coal were tested. The lignite was collected from Beizao coal mine located in North China and the anthracite was collected from Kabuliang coal mine located in Northwest China. The sealed coals were delivered to the laboratory as rapidly as possible. The surface was removed and the interior core was crushed in a vacuum glove box. Then the coal particles ranging from 0.18 to 0.38 $\mathrm{mm}$ were sieved for tests. The proximate analysis of the samples is listed in Table-1.

For avoiding effects of moisture in coal, we dried coal particles at $40{ }^{\circ} \mathrm{C}$ under a vacuum condition. The drying process continued until the mass change of the coal sample was less than $0.1 \%$ per hour. We added different amount of $\mathrm{FeS}_{2}$ to initial dried coal particles to make blended coal samples. The weight percentages of $\mathrm{FeS}_{2}$ in blended coal sample were 3, 5 and $7 \%$.

Testing system: The testing system consisted of a facility for simulation of coal oxidation and a temperature logger, as shown in Fig. 1. The simulation facility is an enclosure capable of programmed temperature control, a gas tube and a coal 
TABLE-1

PROXIMATE ANALYSIS OF COAL SAMPLES

\begin{tabular}{|c|c|c|c|c|c|c|c|}
\hline Coal samples & $\mathrm{M}_{\mathrm{ad}}(\%)$ & $\mathrm{A}_{\mathrm{ad}}(\%)$ & $\mathrm{V}_{\mathrm{ad}}(\%)$ & $\mathrm{FC}_{\mathrm{ad}}(\%)$ & $\mathrm{Q}_{\text {net, ad }}(\mathrm{kJ} / \mathrm{g})$ & $\mathrm{H}_{\mathrm{ad}}(\%)$ & $\mathrm{S}_{\mathrm{td}}(\%)$ \\
\hline Beizao lignite & 9.86 & 20.65 & 30.01 & 34.08 & 21.81 & 4.49 & 0.37 \\
\hline Kabuliang anthracite & 1.12 & 6.86 & 11.76 & 80.26 & 32.93 & 3.78 & 0.23 \\
\hline
\end{tabular}

reaction vessel. The temperature logger was a set of thermocouples and an analyzing system.

The programmed temperature enclosure provides a surrounding environment at an accurate and uniform temperature by means of a gas bath. The dry air temperature was the same as the surrounding temperature because the dry air was preheated before flowing into the coal reaction vessel. Preheating was achieved by passing the air through a $50 \mathrm{~m}$ copper tube located inside the programmed enclosure. The coal reaction vessel was made of pure copper, which has a good thermal conductivity. At its bottom, there is a $20 \mathrm{~mm}$ high gas buffer space segmented with a $0.15 \mathrm{~mm}$ stainless steel mesh aperture, as shown in Fig. 1b. This buffer space ensures a steady, dry air flow into the coal sample. Thermocouple 1, fixed at the center of the thermally programmed enclosure, was used to monitor the surrounding temperature while thermocouple 2, fixed at the center of the coal reaction vessel was used to monitor the coal temperature.

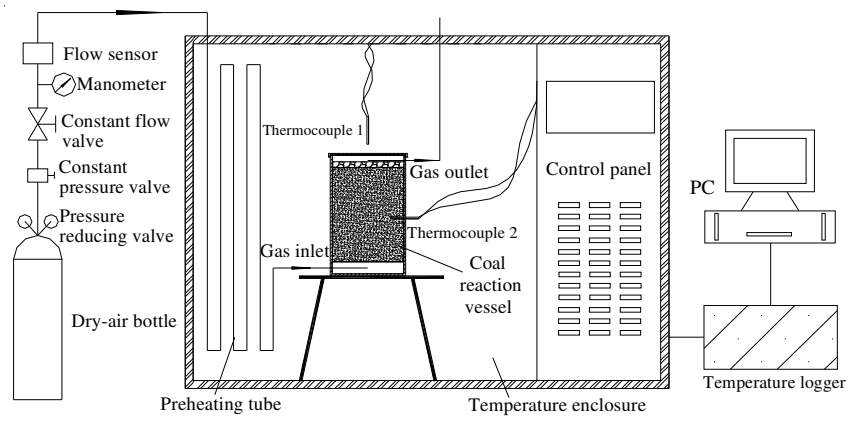

(a) Testing system

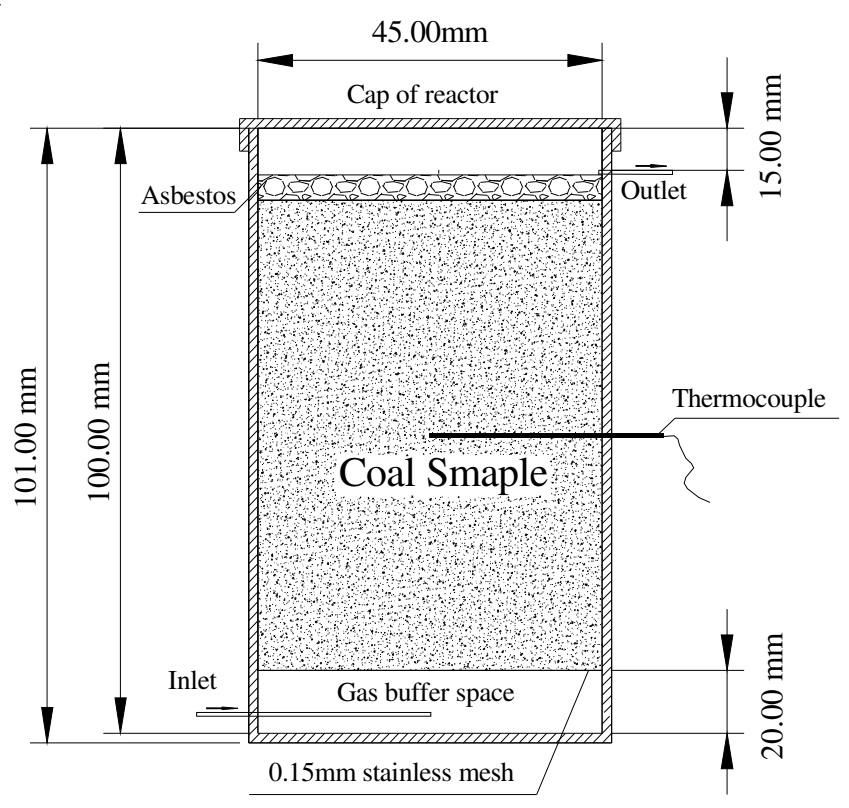

(b) Coal reaction vessel

Fig. 1. Schematic diagram of the testing system
Testing procedures: The tests were carried on according to the procedures as follows.

(1) We put $50 \mathrm{~g}( \pm 0.01 \mathrm{~g})$ of coal sample into the coal reaction vessel. A thin bed of asbestos was laid on top of the coal sample to prevent the gas tube from becoming plugged.

(2) The programmed temperature enclosure was set to run at a constant temperature of $40{ }^{\circ} \mathrm{C}$ while dry air with an oxygen concentration of $20.96 \%$ was permitted to flow through the coal reaction vessel at a rate of $8 \mathrm{~mL} / \mathrm{min}$. The temperature logger was used to continuously monitor the coal and surrounding temperatures.

(3) When coal temperature reached $40^{\circ} \mathrm{C}$, the programmed temperature enclosure was set to run at a programmed heating rate of $0.8^{\circ} \mathrm{C} / \mathrm{min}$ while the flow rate of dry air was maintained at $8 \mathrm{~mL} / \mathrm{min}$. The reaction intensity at low temperatures is weak and corresponding oxygen requirement is small. The flow rate at $8 \mathrm{~mL} / \mathrm{min}$ not only satisfies the oxygen requirements in this stage, but also avoids heat loss, which is key for the development of coal self-heating.

(4) When coal temperature reached $70{ }^{\circ} \mathrm{C}$, the programmed temperature enclosure continued heating at a rate of $0.8^{\circ} \mathrm{C} / \mathrm{min}$ but the flow rate of dry air was changed to $96 \mathrm{~mL} /$ $\min$. The reaction intensity and corresponding oxygen requirement increases with the rise of coal temperature. So we changed the rate of dry air to a different rate at $96 \mathrm{~mL} / \mathrm{min}$ after $70^{\circ} \mathrm{C}$.

(5) We ended the experiment when coal temperature was $5{ }^{\circ} \mathrm{C}$ higher than the surrounding temperature.

\section{RESULTS AND DISCUSSION}

Based on the results, the temperature rising trends of initial and blended coal samples are shown in Figs. 2 and 3. It indicates $\mathrm{FeS}_{2}$ inhibits the coal oxidation process in some degree under dry and low-temperature conditions. A similar phenomenon was also found in Pietrzak and Wachowska's investigation ${ }^{17}$. They proposed that coal reactivity usually decreased with an increase in coal rank but they found that a lignite sample having a sulfur content of $11.4 \%$ had very low reactivity.

In general, $\mathrm{FeS}_{2}$ can react with $\mathrm{O}_{2}$ and $\mathrm{H}_{2} \mathrm{O}$. However, the reactivity of $\mathrm{FeS}_{2}$ is low and it is almost inert under dry and low-temperature conditions. During coal oxidation, these nonreactive sulfur components form a film that covers the coal surface. It plugs pores and crannies in the coal and inhibits heat transfer and the contact between the coal and $\mathrm{O}_{2}$. As a result, coal oxidation is inhibited by these sulfur components under dry and low-temperature conditions.

There is a critical weight percentage of $\mathrm{FeS}_{2}$ added. The results show the effects are similar for blended coal samples at weight percentages of 5 and $7 \%$. Under dry and low-temperature conditions, $\mathrm{FeS}_{2}$ influence the spontaneous combustion of coal through inhibiting heat transfer and the contact between coal and oxygen. If the amount of $\mathrm{FeS}_{2}$ is enough to form a layer on coal particle, the inhibition degree will not increase 


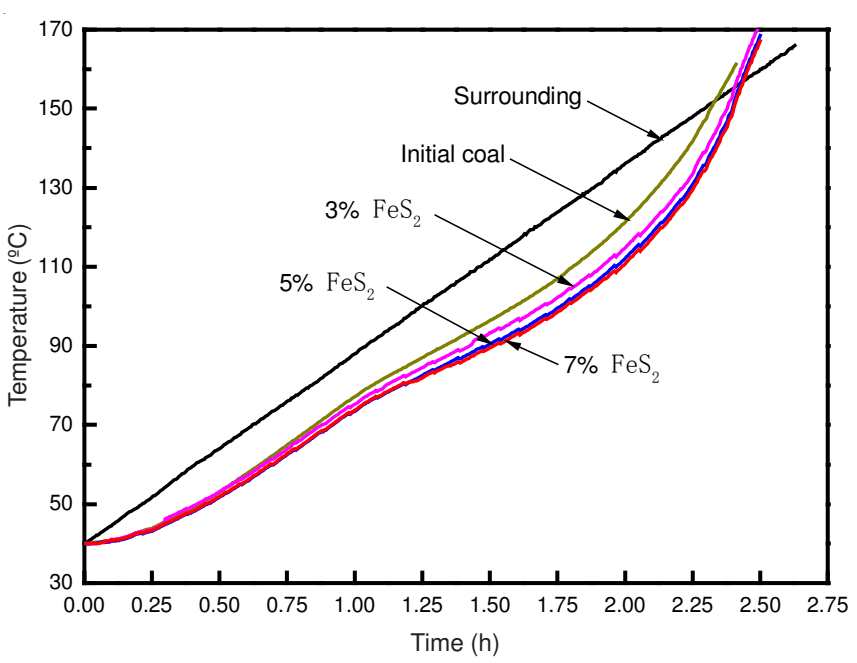

Fig. 2. Temperature rising trends of initial and blended Beizao lignite

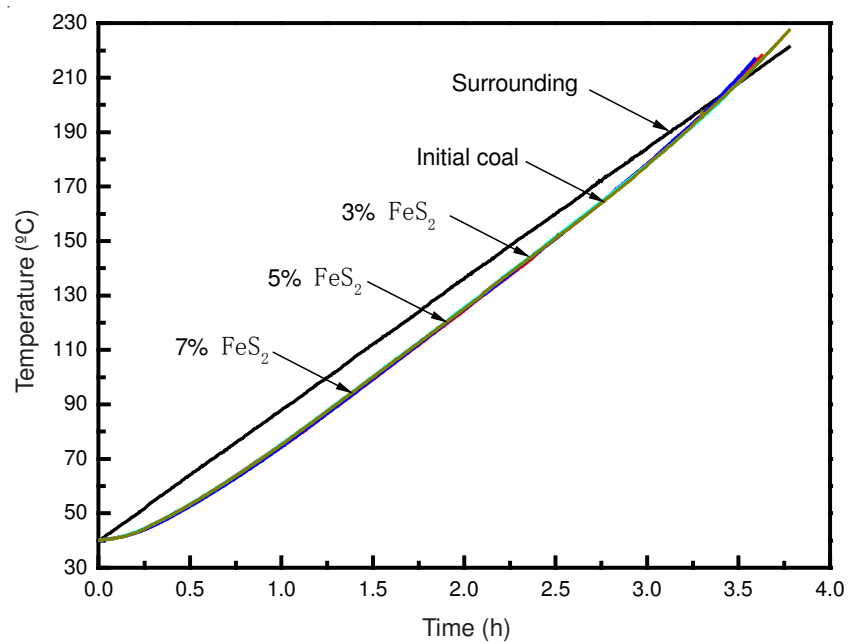

Fig. 3. Temperature rising trends of initial and blended Kabuliang anthracite

with more $\mathrm{FeS}_{2}$ added. It indicates the change of temperature rising trend is due to the inhibition on the transfer and contact of active groups.

\begin{tabular}{|c|c|c|}
\hline \multicolumn{3}{|c|}{$\begin{array}{c}\text { TABLE-2 } \\
\text { CROSSING POINT TEMPERATURES OF } \\
\text { INITIAL AND BLENDED COAL SAMPLES }\end{array}$} \\
\hline $\begin{array}{c}\text { Proportion of } \\
\mathrm{FeS}_{2}(\%)\end{array}$ & $\begin{array}{c}\text { Beizao } \\
\text { lignite }\left({ }^{\circ} \mathrm{C}\right)\end{array}$ & $\begin{array}{c}\text { Kabuliang } \\
\text { anthracite }\left({ }^{\circ} \mathrm{C}\right)\end{array}$ \\
\hline 0 & 152.0 & 204.0 \\
\hline 3 & 155.3 & 203.0 \\
\hline 5 & 156.5 & 207.5 \\
\hline 7 & 157.0 & 207.0 \\
\hline
\end{tabular}

The sulfur components play different inhibition effects on spontaneous combustion of coal. It is more obvious for lower ranks of coal. For higher ranks of coal, the effects is not very obvious. The results show the temperature rising trends of initial and blended Kabuliang anthracite samples are similar. The curves nearly coincide for coal samples with different weight percentage of $\mathrm{FeS}_{2}$. There are more types and amount of active groups in low ranks of coal than high rank ones. The $\mathrm{FeS}_{2}$ covering coal particles can inhibit contact and reaction between coal and $\mathrm{O}_{2}$ at a bigger degree. As a result, the inhibition effects on temperature rising are more obvious as well. For equal rank coal samples, the coal with the higher sulfur content usually has a smaller rate of temperature rise and a higher crossing point temperature than the coal with a lower sulfur content. For example, we found Changguang gas rich coal, with a high sulfur content of $5.01 \%$, had a crossing point temperature of $180.1{ }^{\circ} \mathrm{C}$, which was higher than the other coal samples with a very similar rank and moisture content.

\section{Conclusion}

The crossing point temperature of initial and blended dried coal samples were tested using a self-designed equipment. The results indicate that the effects of sulfur components depend on reaction conditions and coal ranks. The reactions of sulfur components in coal occur at an appropriate moist and temperature condition and enhance coal self-heating. However, under dry and low temperature conditions, the non-reactive sulfur components cover coal particles and inhibit heat transfer and the contact between coal and oxygen. Consequently, they inhibit temperature rising and result in the increase of crossing point temperature. The inhibition degree is associated to coal ranks and weight percentage of $\mathrm{FeS}_{2}$ added. It is usually more obvious for low ranks of coal.

\section{ACKNOWLEDGEMENTS}

The authors appreciated the financial supports provided by the National Natural Science Foundation of China (No. 51204172 and No. 51134020), the Project Funded by the Priority Academic Program Development of Jiangsu Higher Education Institutions and the Fundamental Research Funds for the Central Universities (No. 2011RC06).

\section{REFERENCES}

1. O.I. Ogunsola and R.J. Mikula, Fuel, 70, 258 (1991).

2. V. Mahadevan and M.A. Ramlu, J. Mines Metals Fuels, 357 (1985).

3. W. Sujanti, D.K. Zhang and X.D. Chen, Combust. Flame, 117, 646 (1999).

4. S. Saha, B.K. Sharma, P. Chavan, S. Datta, G. Sahu, B.K. Mall and T. Sharma, Asian J. Chem., 23, 4335 (2011).

5. Y. Tang, Z. Li, Y. Yang, N. Song and D. Ma, Asian J. Chem., 25, 441 (2013).

6. B.K. Saikia, Asian J. Chem., 23, 1887 (2011).

7. F.E. Huggins, G.P. Huffman, G.R. Dunmyre, M.J. Nardozzt and M.C. Lin, Fuel Process. Technol., 15, 233 (1987).

8. M.M. Wu, G.A. Robbins, R.A. Winschel and F.P. Burke, Energy Fuel, 2, 150 (1988).

9. S. Yani and D. Zhang, Fuel, 89, 1700 (2010).

10. J. Yan, L. Xu and J. Yang, J. Anal. Appl. Pyrol., 82, 229 (2008).

11. A. Küçük, Y. Kadioglu and M.S. Gülaboglu, Combust. Flame, 133, 255 (2003).

12. Mahidin, H. Usui, S. Ishikawa and Hamdani, Int. J. Coal Prep. Util,, 22, 81 (2002).

13. Y. Kadioglu and M. Varamaz, Fuel, 82, 1685 (2003).

14. S. Mandal, R.S. Prasad and L.K. Verma, J. Sci. Ind. Res. India, 65, 518 (2006).

15. R. Nubling and H. Wanner, J. Gasbeleucht, 58, 515 (1915).

16. X.D. Chen and L.V. Chong, Process Saf. Environ., 76, 90 (1998).

17. R. Pietrzak and H. Wachowska, Fuel, 82, 705 (2003). 